\title{
MISSÕES JESUÍTICAS COLONIAIS
}

\section{Paula Caleffi Giorgis*}

Em uma época onde as relações entre Península Ibérica e América ainda eram travadas a nível de colônia e metrópole, encontramos o trabalho da ordem jesuítica na América, principalmente à nível de missionalização, como bastante relevante, não somente no aspecto de relações entre os novos súditos e a coroa, mas também como no caso espanhol, de típicos defensores das fronteiras do Império.

Neste artigo vamos tratar do início da transformação de uma sociedade étnica americana, em uma sociedade reduzida pelos padres jesuítas.

Esta sociedade conhecida como chiquitana localizava-se no que hoje conhecemos como território da Bolívia, mais precisamente na Amazônia Boliviana.

O trabalho missional e as reduções com os índios chiquitos teve início a partir de uma solicitação feita pelos próprios membros das parcialidades indígenas ao então governador da Província, Augustin de Arce, para que lhes concedesse proteção através da permissão à implantação das missões jesuíticas.

Os chiquitos vinham sofrendo ataques de um lado pelas bandeiras paulistas, que tinham o objetivo de capturar indígenas para vender no mercado brasileiro, como por exemplo a bandeira de 1682 comandada por Pascoal Moreira Cabral; e por outro lado os chiquitos também vinham sendo capturados como força de trabalho para as encomiendas dos cruzenhos.

* Curso de Pós-Graduação em História - IFCH PUC-RS Porto Alegre-RS.

Estudos Ibero-Americanos. PUCRS, v. XVIII, n. 2, p. 79-84, dezembro, 1992 
Assim assediados por portugueses e espanhóis, os chiquitos em 1690, enviam mensageiros ao governador, solicitando proteção. O governador recomenda, então, ao missioneiro, de mesmo sobrenome. José de Arce, que se responsabilize pela missionalização deste grupo étnico.

O Padre Fernandes (S. J.) em sua obra sobre as Reduçōes Chiquitanas, coloca, inclusive que os habitantes de Santa Cruz tentaram impedir que se realizasse o projeto de missão entre os chiquitos. Obviamente não querendo que os jesuítas se antepusessem entre eles e a fonte de mão-de-obra para as suas encomiendas (Fernandes, 1896, p. 83).

No entanto o padre segue adiante com a sua missão, e os primeiros indigenas com quem tem contato pertencem à parcialidade dos Piñocas.

Devemos levar em consideração que a implantação das missões e do processo reducional, ocorreu por solicitação dos indigenas, o que facilitou muitíssimo o trabatho dos jesuitas. Hoffman, no seu trabalho, cita-nos opiniões de dois jesuitas missioneiros sobre a implantação de reduções entre os chiquitos.

Segundo o padre missioneiro Schmid, os chiquitos materialmente não tinham motivos para desejar a redução, devido a que se encontravam muito bem na floresta, gozando de plena liberdade, nunca sentiam fome, posto que haviam muitos peixes nos rios e muitos animais em terra firme como também pássaros de toda classe (Schmid, In: Hoffman, 1979, p. 5).

$\mathrm{Na}$ opinião de Schmid, o motivo pelo qual os chiquitos se sujeitaram ao processo reducional, não era outro se não, que, o próprio Deus thes havia aberto os olhos para que salvassem suas almas.

Já o missioneiro Knogler coloca-nos que a vida dos chiquitos selvagens, transcorria em uma eterna insegurança, devido as rivalidades entre os grupos. No entanto para eles a guerra era uma espécie de esporte, de modo que não sofriam excessivamente com o risco de invasões por parte das parcialidades vizinhas. Em contrapartida tinham um medo enorme dos espanhóis e dos portugueses. Se os espanhóis nâo houvessem aprisionado os chiquitos durante o século XVII, levando-thes como escravos às suas granjas e estâncias próximas de Santa Cruz, os jesuítas nâo haveriam tito tanto êxito com suas missões (Knogler, In: Hoffman, 1979, p. 121-186).

Ressaltamos o senso de realidade de Knogler pois, talvez o missioneiro não compreendesse que a guerra entre as parcialidades indigenas, é eminente no cotidiano das sociedades ditas primitivas ou igualitárias, porém, o padre, tem completa noção de que este não foi motivo bastante para ajudar na obra missional, enquanto que as bandeiras paulistas e as encomiendas espanholas, sim foram decisivas.

Devido ao papel desempenhado pelo chamá, na tribo, era ele quem representava maior resistência frente ao processo de missão. Não nos referimos aqui, aos 
chamáns pertencentes às parcialidades que solicitaram serem reduzidas pelos jesuítas, devido à que, estes, provavelmente tiveram a sua resistência diminuída pelo montante do grupo, dada a necessidade de proteção. No entanto o processo de missionalizaçâo nunca cessou, enquanto houve às reduções jesuíticas com os chiquitos. E posteriormente a redução de todas as parcialidades que solicitaram a sua intervenção, os jesuitas partiram para a reduçâo de outros grupos, também habitantes da regiâo.

Caça espiritual ou rancherias, era o nome dado pelos próprios jesuítas à este tipo de missão, que consistia no seguinte: durante a época seca, entre os meses de maio até setembro, os padres saiam acompanhados de cinqüenta ou sessenta índios reduzidos, com o objetivo de encontrar parcialidades selvagens, atrair-las ao povoado e evangelizá-las. Knogler explica um fato muito importante neste método:

"Los primeros (indios) que se convierten a la fe católica son instruidos con chinco acerca del valor inestimable que el hombre tiene a la causa de su alma inmortal. Deben saber que el hombre es la criatura mas perfecta. muy por encima de todas las otras, para que tengan mucho aprecio por ellos mismos y por los otros y se sientan estimulados a contribuier a lá salvación de aquellos que vivem todavia en las sielvas.

"Es imprescindible inculcarles esta convicción, pues el misionero na tendrá otra persona que le agude en esta tarea de convertir a los selvajes que uno a otro de ellos mismos" (Knogler, In: Hoffman, 1979, p. 171).

Os missioneiros, Fernandez e Knogler, descrevem as rancherías de maneira diferente; para Fernandez é como se bastasse que o padre e os indígenas cristãos chegassem à uma parcialidade de selvagens, contando-les de Deus e do Céu, ensinando-lhes o fim religioso para o qual haviam sido criados e viviam neste mundo, e a necessidade de abraçar a lei de Cristo para viver eternamente feliz (Fernández, 1986, p. 221).

Guiando-nos pelas palavras do missioneiro, parece-nos que o processo de rancheria dependia simplesmente de que os índios cristãos e o padre dessem a conhecer às coisas divinas, aos indios selvagens.

Já ao lermos o relato feito por Knogler, notamos que o processo era muito mais complexo; segundo o padre, esta gente (os índios) não são capazes de, pelo menos, no início de um ensino religioso, compreender um argumento. Devemos por tanto, buscar outro método para implantar-les o conhecimento, à adoração e o temor à Deus. Quer dizer devemos fazer uso de coisas exteriores que saltem à vista e aos ouvidos, e que se possa tocar com as mãos, até que suas mentes se desenvolvam neste sentido (Knogler, In: Hoffman, 1979, p. 32). 
Os missioneiros para tentar convencer a parcialidade indígena, ao tomar contato com esta, deveriam fazer seu discurso. Este, segundo Fernandez, deveria ser veemente e se, o missioneiro conhecia a língua dos indígenas ou tinha um intérprete de confiança, era a sua oportunidade. No entanto se isto não acontecia o missioneiro tinha chances de impressioná-los com o êxtase do seu discurso e de alguma imagem, se sacava na hora adequada (Fernandez, 1896, p. 18).

Knogler, afirma ainda que para demonstrar que o nivel de vida nas reduções era superior, deveríam levar-se presentes aos selvagens, como machados de ferro e facas (Knogler, In: Hoffman, 1979, p. 23).

Analisando as declaraçôes dos jesuítas, deparamo-nos com um homem, o missioneiro, treinado em falar e discursar horas sem parar. Devemos levar em consideração a importância da capacidade de discurso, entre as sociedades primitivas, este elemento é fator de prestígio entre estas sociedades, pois toda a sobrevivência da sua sociedade e a reprodução da mesma, depende da transmissão dos seus conceitos. Isto ocorre através da palavra e também através do rito. E, é exatamente o que completa o discurso do jesuíta, um ambiente ritual, onde o padre mostra imagens a povos não cristãos, os quais, encontram-se meoclados, entre eles, indígenas habitantes das reduções.

Normalmente nas sociedades primitivas, o responsável pela transmissão das regras e conceitos é o chamán, profundo conhecedor dos mitos da sociedade, e é ele também, o líder ritual.

Uni-se à isto, outro fator favorável ao jesuíta, a distribuição de machados de ferro e facas por parte dos padres, posto que estes artefatos possuem enorme valor entre os indígenas por facilitarem seus trabalhos.

Outro elemento que também era fonte de prestígio e que, o jesuíta soube manipular a seu favor é o relativo à cura de doenças, função que na tribo também era desenvolvida pelo chamán.

O próprio padre Fernandez reconhece que a cura dos doentes trazia, aos missioneiros bastante crédito entre os selvagens (Fernandez, 1896, p. 32).

Podemos concluir que os missioneiros possuíam o conhecimento dos remédios naturais utilizados pelos chamáns, devido a convivência com os primeiros chiquitos que solicitaram a redução e acrescentaram a estes remédios, os sais e os medicamentos que traziam com eles, da Europa.

Assim notamos que o missioneiro reunia os atributos, fonte de prestígio, normalmente relacionados ao chamán, e outros mais.

Segundo Hoffman (1979, p. 28), em geral a atitude do grupo obedecia a critérios do chefe espiritual deste. Notamos que a falta de um cacique mais definido em 
época de paz, faz com que os jesuítas não tenham a opção de fazerem-se aliados de um chefe, uma liderança paralela à chamânica.

Por conseqüência os jesuítas não podem aliar-se a uma liderança paralela e, desterrar a liderança religiosa chamânica da tribo, tendo então que ganhar o seu reconhecimento e provar, também a este chamán, que os atributos pertencentes aos padres, são superiores.

Não encontramos, nos relatos conhecidos dos missioneiros, nenhuma menção à alguma revolta organizada por chamáns dentro das reduções. Porém Knogler menciona que tiveram muito trabalho, os missioneiros, em suprimir os costumes referentes aos ritos de cura protagonizados pelos chamáns; devido a que, os índios no seu afán de fazerem-se curar, se valiam de qualquer subterfúgio (Knogler, In: Hoffman, 1979, p. 155).

A parte referente as rancherias, era apenas um parte do processo, pois consistia em convencer aos "selvagens", a acompanhar o padre e os índios já reduzidos, à redução, para viver ali. Porém o trabalho mesmo, segundo Fernandez, começava dentro das reduçôes, onde "os bárbaros novos na fé", eram educados, não apenas pelo padre cura, mas também por todos os velhos cristãos que viviam ali que "agodaban a quitarles las malas costembres, hacerles oluidar las antiguas superticiones y reducirlos a la estrechez de la ley y vida cristiana" (Fernandez, 1896, p. 144).

Nem sempre as rancherias com os chiquitos, tiveram êxito, houveram ocasiões onde os índios das reduções foram atacadas em meio a uma rancheria e massacrados, inclusive com o missioneiro (Hoffman, 1979, p. 22).

Houve casos também, onde se fizeram necessários mais de uma tentativa em certas parcialidades, para que estas, os acompanhassem. Fazia a rancheria em um ano, no entanto não era o suficiente, os "selvagens" se negavam a acompanhá-los, porém os escutavam e aceitavam sua visita. Então se fazia necessário que no próximo ano, na próxima estação seca, se fizesse nova rancheria nesta parcialidade (Knogler, In: Hoffman, 1979, p. 163).

Os índios chamados selvagens, eram levados, como vimos às reduções já existentes, para que convivessem com os indigenas cristãos. Normalmente uma nova redução era formada pelos indigenas já cristianizados, pertencentes à uma redução que estivesse com sua lotação esgotada.

Com isto podemos concluir que, o processo de missão e redução, que os jesuítas empreenderam com os chiquitos, foi bastante peculiar, e até podemos dizer facilitado, devido às condições que ocorreu: primeiro a redução de parcialidades que haviam expressado o desejo que isto ocorresse. Depois então, quando começaram a 
missão com grupos que ainda estavam em estágio igualitário e, não haviam solicitado à redução, era-thes possível convencer e transladar estas parcialidades a conviverem com os índios já cristãos, nas reduções. isto significava possuir um espaço físico disposto para, o que os padres chamavam, civilização e evangelização dos indios.

\section{REFERÊNCIAS BIBLIOGRÁFICAS}

FERNANDEZ, Patrício S. J. Relación historial de las misiones de indios chiquitos. Asunción del Paraguay: Libreria y Casa Editora de A. Uribe y Comp, 1896.

HOFFMAN, Werner. Las misiones jesuiticas entre los chiquitanos. Buenos Aires: Fund. para la Educación la Ciència y la Cultura, 1979.

KNOGLER, P.J.S.J. "Relato sobre el paris y la nación de los chiquitos". In. Hoffman, W. op. cit., p. 121-186.

SCHMID, M.S.J. "Carta del 19 de febrero de 1746". In: Hoffman, W., op. cit., p. 5. 